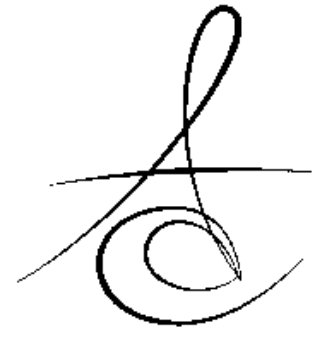

Makale Kodu/Article code: 2269

Makale Gönderilme tarihi: 14.06.2015

Kabul Tarihi: 03.09.2015

\section{MİNEYE FARKLI YÜZEY PÜRÜZLENDİRME METOTLARIYLA YAPIŞTIRILMIŞ BRAKETLERİN MAKASLAMA AĞLANMA DAYANIMLARI}

\author{
SHEAR BOND STRENGTHS OF BRACKETS BONDED TO ENAMEL WITH \\ DIFFERENT SURFACE CONDITIONING METHODS
}

\section{öz}

Amaç: Bu in vitro çalışmanın amacı dört farklı pürüzlendirme yönteminin ortodontik braketlerin makaslama bağlanma dayanımı üzerine etkisini incelemektir.

Metod: Bu çalışmada 40 yeni çekilmiş üst 1. premolar insan dişi kullanıldı ve mine yüzey tedavi tipine bağlı olarak rastgele dört gruba ayrıldı $(n=10)$ : I, asitle pürüzlendirme; II, Er:YAG lazer; III, Er:YAG lazer + asit pürüzlendirme; IV, alüminyum oksit ile kumlama. Dişler dikey bir pozisyonda kendi kendine sertleşen akrilik içerine gömüldü ve böylece kronları açığa çıktı Paslanmaz çelik premolar braketleri standart bir işlemle tüm dişlere yapıştırıldı ve tüm dişler SBS testine tabii tutuldu. Sonra, her bir örnek için artık adeziv indeksi (adhesive remnant index -ARI) değerlendirildi. Kırılma modları miktar olarak bir stereomikroskopla ve morfolojik olarak da bir tarama elektron mikroskopu (scanning electron microscope-SEM) altında değerlendirildi. İstatistiksel analiz anlamlılık seviyesi 0.05 'de kararlaştırılarak tek yönlü varyans analizi ve Tukey çoklu karşılaştırma testi ile yapıldı.

Bulgular: Her bir grup için ortalama makaslama test değerleri sırasıyla şöyledir: I, $10.21 \pm 0.8$; II, $9.33 \pm$ 1.2; III, $13.46 \pm 0.7$; IV, $3.36 \pm 0.6$. III. grup (ErYAG lazer + asit pürüzlendirme) en yüksek SBS değerlerini gösterirken, IV. grup (kumlama) en düşük SBS değerlerini gösterdi ve kumlama ve diğer gruplar arasında istatistiksel olarak anlamlı bir farklılık gözlendi. ARI skorlarının değerlendirilmesi III.grupta mine yüzeyinde daha fazla adezivin kaldığını gösterdi.

Sonuç: Mevcut bulgular yüzey pürüzlendirme için uygun parametrelerle Er:YAG lazerden faydalanmanın mümkün olduğudur.

Anahtar Kelimeler: Makaslama bağlanma dayanımı, kumlama, Er-YAG lazer, asitle pürüzlendirme, ortodontik bağlanma.

\section{ABSTRACT}

Aim: The purpose of this in vitro study is to evaluate the effect of four different conditioning methods on the shear bond strength (SBS) of orthodontic brackets.

Methods: In this study 40 freshly extracted upper first premolar human teeth were used and randomly divided into four groups $(n=10)$, according to the type of the enamel surface treatment: I, acid etching; II, Er:YAG laser; III, Er:YAG laser + acid-etching; IV, sandblasting with aluminum oxide. The teeth were embedded in self cure acrylic in a vertical position so that the crowns were exposed. Stainless steel premolar brackets were bonded to all teeth with a standard procedure and all teeth were subjected to SBS test. The adhesive remnant index (ARI) was then evaluated for each specimen. Failure modes were assessed quantitatively under a stereomicroscope and morphologically under a scanning electron microscope (SEM). Statistical analysis was performed using oneway analysis of variance and the post hoc Tukey test, with the significance level set at 0.05 .

Results: Mean shear test values for each group were as follows: I, $10.21 \pm 0.8$; II, $9.33 \pm 1.2$; III, $13.46 \pm$ 0.7 ; IV, $3.36 \pm 0.6$. While group III (ErYAG laser + acid-etched) showed the highest SBS values, group IV (sandblasting) showed the lowest SBS values and a statistically significant difference was observed between sandblasting and the other groups. The evaluation of ARI scores demonstrated more adhesive was left on the enamel surface with Group III.

Conclusion: The current findings indicate that it is possible to benefit from Er:YAG laser with appropriate parameters for surface conditioning.

Key-words: Shear bond strength, sandblasting, ErYAG laser, acid-etching, orthodontic bonding

\footnotetext{
${ }^{*}$ Department of Orthodontics, Center for Dental Sciences, Gulhane School of Medicine

** Department of Endodontics, Faculty of Dentistry, Bezmialem Vakıf University,

*** Marasal Cakmak Military Hospital Dental Center, 


\section{GíRİş}

Sabit ortodontik tedavinin başarısı, tedavi aşamasında kullanılan braketlerin tutuculuğuyla doğrudan ilişkilidir. Braketin tutuculuğu ise; braket tabanındaki pürüzler ile diş yüzeyinde oluşturulan pürüzler arasındaki mekanik bağlantının kuvvetli olmasına dayanmaktadır. ${ }^{1}$ Geçmişten günümüze birçok mine yüzeyi pürüzlendirme yönteminden faydalanılmıştır. ${ }^{2-7}$ Bunlardan 1955 yılında Buonocore ${ }^{8}$ tarafından tanitılan ve mikropörözitelerin oluşturulması için kullanılan ortofosforik asit, geleneksel bir yöntem olup kullanımı en yaygın olanıdır. Ortofosforik asitle pürüzlendirme işleminin başarısı, dişlerin izolasyonu ve pürüzlendirilmiş mine yüzeyinin tükürük ya da su ile kontaminasyonunun engellenmesine bağlıdır. ${ }^{9}$ Son yıllarda, asitle pürüzlendirme yöntemine karşı diş sert dokularının pürüzlendirilmesinde kumlama (air-abrazyon) ve lazer uygulamaları gibi alternatif metotlar üzerinde çalışılmaktadır. İlk olarak Black tarafından 1945 'te ortaya çıkarılan kumlamanın temel prensibi yüksek ivmeli hava basınc tarafından fırlatılan keskin odağa sahip çok küçük alüminyum oksit (Al2O3) partiküllerinin kinetik enerjisinden yararlanmaktır. ${ }^{10}$ Lazer pürüzlendirme yöntemlerinde ise, yüzeydeki hidroksiapatit matriks içinde sıkışmış bulunan su sürekli buharlaşmakta ve bu esnada mikro-patlamalar meydana gelmektedir. Kullanılan lazerin tipine ve yüzeye uygulanan enerji miktarına bağlı olarak mine yüzeyinde $10-20 \mu \mathrm{m}$ derinliğinde, asit uygulamasındakine benzer bir pürüzlenme ve düzensizlik meydana gelmektedir. ${ }^{11}$ Kumlama ve lazer uygulanarak mine bağlanma dayanımının değerlendirildiği geçmiş çalışmalarda çelişkili sonuçlar bulunmuştur. ${ }^{10-16}$ Bazı çalışmalarda kumlama ve lazer uygulamalarının asit uygulanmasına alternatif olacağı görüşü var iken, başka çalışmalarda bu görüşün tersi iddialar ortaya atılmıştır. ${ }^{17-27}$ Sonuç olarak, bugüne kadar yapılan farklı çalışmalardan ortaya çıkan ortak bir görüş mevcut değildir. Bu nedenle, bu çalışma dört farklı pürüzlendirme yönteminin ortodontik braketlerin mineye makaslama bağlanma dayanımı üzerine etkisini incelemeyi amaçlamaktadır.

\section{GEREÇ VE YÖNTEMLER}

Çalışmamız ortodontik tedavi amacıyla yeni çekilmiş, üzerinde çürük, restorasyon, mine çatlağı olmayan ve herhangi bir kimyasala maruz kalmamış 40 adet insan üst çene 1 . küçük azı dişi üzerinde laboratuar şartlarında gerçekleştirildi. Diş yüzeyinde çatlak varlığı 20x büyütme değerine sahip stereomikroskop (Discovery V8 Stereo,Carl Zeiss MicroImaging $\mathrm{GmbH}$, Göttingen, Almanya) altında incelenip ve testi engelleyecek mine yüzey yapısına sahip dişler elimine edildi. Dişler yüzeydeki olası plak ve yumuşak doku artıklarını uzaklaştırmak amaçlı su altında fırça yardımıyla temizlendikten sonra, antibakteriyel etki amaçlı \%0.1 timol'lu solüsyonda bekletildi ve ardından distile suya transfer edildi. Dişlerin kökleri mine yüzeyleri açıkta kalacak şekilde akrilik bloklara gömüldü. (Orthocryl, Dentaurum, Ispringen, Almanya) (Resim 1) Pürüzlendirmenin uygulanacağı alanın sınırlandırılması amaçlı, braket alanından daha geniş olacak (4x6) şekilde akrilik pencereler hazırlandı. Tüm gruplarda hazırlanan akrilik bloklar bir araştırmacı (S.E.) tarafından pürüzlendirme istenen bölge yüzeyinde tutulurken, diğer araştırmacı (F.A.S.) hazırlanan akrilik pencere sınırları içerisinde olacak şekilde, pürüzlendirme yöntemini uygulandı. Dişler mine pürüzlendirilme yöntemine göre şu gruplara ayrıldı $(n=10)$ :

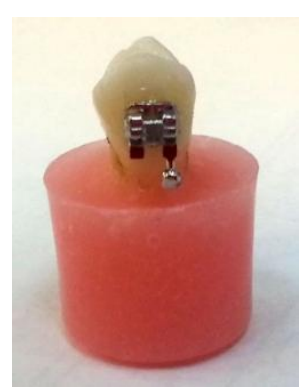

Resim 1. Akrilik blok içine gömülmüş diş

(I) Ortofosforik asit ile pürüzlendirme $(n=10)$. Dişlerin pürüzlendirilmesi için \%37'lik ortofosforik asit (etching solution, ORMCO, USA) jeli 15 saniye uygulandı. Dişler sonra 15 saniye boyunca basınçlı su ile yıkandı ve 15 saniye hava ile kurutuldu.

(II) Er:YAG lazer ile pürüzlendirme $(n=10) .2 W$ gücünde ve orta-kısa darbe modunda (MSP; $100 \mathrm{ms,}$ $10 \mathrm{~Hz}, 2 \mathrm{~W}$ ). Er:YAG lazer (2970-nm wavelength; LightWalker, Fotona, Slovenia), hava ve suyla, kontak modda, pulsasyon enerjisi $120 \mathrm{~mJ}$ olacak şekilde mine yüzeyinden $1 \mathrm{~mm}$ uzaklıktan elle süpürme hareketi yaparak 15 saniye uygulandı (Resim 2).

(III) II. grupta tarif edildiği gibi Er:YAG lazer uygulandı ve devamında dişler \%37'lik ortofosforik asit ile 15 saniye pürüzlendirildi. Ardından dişler basınçlı su

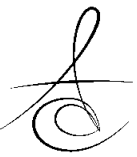


ile 15 saniye boyunca yıkandı ve 15 saniye hava ile kurutuldu.

(IV) Alüminyum oksit ile kumlama $(n=10)$. Kumlama cihazı (Micro-Etcher ERC II, Danville Engineering, San Ramon, California, USA) diş yüzeyine $10 \mathrm{~mm}$ uzaklıktan ve dikey olacak şekilde yerleştirilip, 2,5 bar basınç altında 50 mm boyutunda alüminyum oksiti 3 saniye boyunca püskürttü. Tüm dişler 20 saniye su ile yıkanıp kurutuldu.

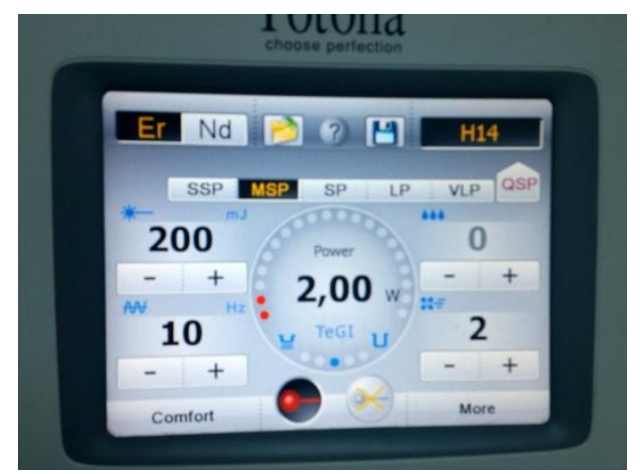

Resim 2. Çalışmada kullanılan lazer cihazı

\section{Ortodontik braketlerin yapıştırılması}

Hazırlanmış diş yüzeylerine ince bir tabaka halinde Transbond XT primeri (3M Unitek, Monrovia, $C A, A B D)$ uygulandı ve 10 saniye boyunca ışık cihazı (Demetron LC, SDS Kerr; light output: $400 \mathrm{~mW} / \mathrm{cm}^{2}$ ) kullanılarak polimerize edildi. Arka yüzeylerine Transbond XT adezivi konan braketler (Rocy Mountain Denver, USA), diş yüzeyinde uygun pozisyona getirilip hafifçe bastırılarak yerleştirildi ve artık adeziv keskin bir küret yardımıyla temizlendi. Adeziv braketin dört bir tarafından 10 saniye olacak şekilde toplam 40 saniye ışıkla polimerize edildi. Hazırlanan örnekler $37^{\circ} \mathrm{C}$ 'de 24 saat distile suda bekletildi. Sonrasında dişlere ağız ortamının ISı ve nem ortamını taklit etmek amacıyla, termal stres uygulamasına geçildi. Bu amaçla sıcaklık dereceleri sabitlenmiş iki ayrı su tankı ve örnekleri bu sulara batıracak şekilde bir düzenek hazırlandı. Hazırlanan örnekler $5^{\circ} \mathrm{C}$ ile $55^{\circ} \mathrm{C}$ sıcaklıktaki su banyolarına sırayla 500 kere batırılarak termal stres oluşması sağlandı. Her bir banyoda bekleme süreleri 20 saniye, banyolar arası transfer süreleri 10 saniye olacak şekilde ayarlandı. Daha sonra dişlere SBS testi uygulanıncaya kadar distile suda muhafaza edildi ve mikroorganizmaların ürememeleri için bu su haftada bir kez değiştirildi. SBS testi uygulanması amacıyla, Instron universal cihazının (Shimadzu Autograph AGIS, Kyoto, Japan) bıçak sırtı şeklinde sonlanan metal ucu, diş-braket ara yüzeyine paralel olarak yerleştirildi ve SBS testi (Shear Bond Strenght, SBS 0.5mm/dak) uygulandı ve elde edilen kırılma değerleri megapaskal (MPa, uygulanan kuvvet (N), yüzey alanına bölünerek) cinsinden kaydedildi (Resim 3). Fraktür analizi için, bağlanma testi sonrası, mine yüzeyleri stereomikroskop (Olympus SZ61; Olympus Optical Co, Tokyo, Japan) 10 x büyütme ile incelendi ve kopmanın meydana geldiği bölgelerinin belirlenmesinde Artun ve Bergland $^{28}$ tarafından tanımlanmış olan ARI indeksi kullanıldı. Skorlama, skor 0: Diş yüzeyinde hiç adeziv kalmamıştır (<10\%); skor 1: Diş yüzeyinde $\% 50$ 'den daha az adeziv kalmıştır; skor 2,: Diş yüzeyinde \%50'den daha fazla adeziv kalmıştır; skor 3: Tüm adeziv diş yüzeyinde kalmıştır (>90\%)

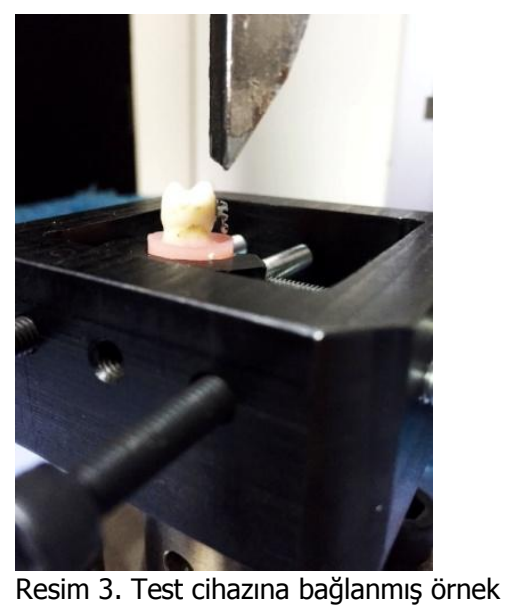

Çalışmamızda, farklı mine pürüzlendirme işlemi uygulanan dişlerin debonding sonrası mine yüzeyinde meydana gelen değişiklikleri değerlendirebilmek amacıyla, dişler altın-paladyum ile kaplanarak tarayıcı elektron mikroskobunda (SEM, Kyky Technology Development, Beijing, China) incelendi.

\section{İstatistiksel analiz}

Tüm istatistiksel hesaplamalar için MS Excel 2003 (MS Excel 2003 (c) 1985-2003 Microsoft Corporation) ve SPSS for Win. Ver 2000 (SPSS INC, Chicago, IL, USA) paket programları kullanıldı. Verilerin normal dağılıma uygunluğu Kolmogorov-Smirnov testi ile değerlendirildi. Gruplar arasında SBS testi açısından belirgin fark olup olmadığı, tek yönlü varyans analizi (One way ANOVA) ile test edildi. Gruplar arasında SBS testi açısından belirgin fark olduğunda hangi grubun farklı olduğu Tukey testi ile belirlendi. Anlamlılık derecesi $p<0.05$ olarak kabul edildi

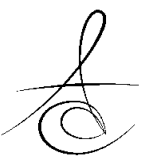




\section{BULGULAR}

Her bir grubun ortalama SBS değerleri, standart sapmaları, maksimum, minumum değerleri Tablo 1 'de sunuldu. Buna göre değerler sırayla; I, $10.21 \pm$ 0.87 ; II, $9.33 \pm 1.20$; III, $13.46 \pm 0.70$; IV, $3.36 \pm$ 0.60 . Gruplar arasında farklılık belirlemek için tek yönlü ANOVA ve Tukey testi uygulandı (Tablo 2; $\mathrm{p}<0.05)$. III. grupta gruplar arasında istatiksel olarak anlamlı ve en yüksek SBS değeri $(13.46 \pm 0.70)$, IV. grupta ise istatiksel olarak anlamlı $(3.36 \pm 0.60)$ en düşük SBS değeri tespit edildi. Grup I ve II arasında istatiksel olarak bir farklılık saptanmadı ( $p>0.05)$.

Tablo 1. Gruplarda saptanan SBS değerleri, standart sapmaları, maksimum, minumum değerleri (MPa).

\begin{tabular}{|c|c|c|c|c|c|c|c|c|}
\hline \multirow{2}{*}{$\begin{array}{l}\text { SBS } \\
\text { (MPa) }\end{array}$} & \multirow[b]{2}{*}{ ฝั } & \multirow[t]{2}{*}{ Ort. } & \multirow{2}{*}{$\begin{array}{l}\text { Std. } \\
\text { Sap. }\end{array}$} & \multirow{2}{*}{$\begin{array}{l}\text { Std. } \\
\text { Hata }\end{array}$} & \multicolumn{2}{|c|}{$\begin{array}{c}\text { 95\% Güven } \\
\text { Aralığı }\end{array}$} & \multirow{2}{*}{ 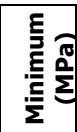 } & \multirow{2}{*}{ 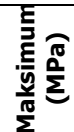 } \\
\hline & & & & & $\begin{array}{l}\text { Alt } \\
\text { Sınır }\end{array}$ & $\begin{array}{l}\text { Üst } \\
\text { Sınır }\end{array}$ & & \\
\hline Grup I & 10 & 10.21 & .879 & .278 & 9.58 & 10.84 & 9.11 & 11.55 \\
\hline Grup II & 10 & 9.33 & 1.209 & .382 & & & 8.01 & 11.26 \\
\hline Grup III & 10 & 13.46 & .704 & .222 & & & 12.54 & 14.70 \\
\hline Grup VI & 10 & 3.36 & .601 & .190 & 2.93 & 3.79 & 2.36 & 4.58 \\
\hline Total & 40 & 9.09 & 3.79 & .599 & 7.88 & 10.30 & 2.36 & 14.70 \\
\hline
\end{tabular}

Tablo 2.Gruplar arası karşılaştırmalar

\begin{tabular}{|l|l|l|l|l|}
\hline Grup & Grup I & Grup II & Grup III & Grup IV \\
\hline Grup I & - & $\mathrm{NS}(0.13)$ & $*(0.025)$ & $*(0.033)$ \\
\hline Grup II & $\mathrm{NS}(0.13)$ & - & $*(0.024)$ & $*(0.030)$ \\
\hline Grup III & $*(0.025)$ & $*(0.030)$ & - & $*(0.025)$ \\
\hline Grup IV & $*(0.034)$ & $*(0.025)$ & $*(0.022)$ & - \\
\hline
\end{tabular}

NS: İstatiksel olarak anlamsız, $\mathrm{p}>0.05 *$ : İstatiksel olarak anlamlı, $\mathrm{p}<0.05$

Fraktür analiz değerleri Tablo 3'de gösterildi. Grup 3'de 50\%'den fazla artık adhesive saptanırken, grup IV'de hemen hemen hiç artık saptanmadı. Grup I ve II'de ise $50 \%$ den az artık adhesive saptandı.

Tablo 3:Grupların ARI indeks değerleri

\begin{tabular}{|l|l|l|l|l|}
\hline Grup & $\mathbf{0}$ & $\mathbf{1}$ & $\mathbf{2}$ & $\mathbf{3}$ \\
\hline Grup I & 3 & 7 & 0 & 0 \\
\hline Grup II & 2 & 8 & 0 & 0 \\
\hline Grup III & 0 & 1 & 6 & 3 \\
\hline Grup IV & 9 & 1 & 0 & 0 \\
\hline
\end{tabular}

Skor 0: Diş yüzeyinde hiç adeziv kalmamıştır $(<10 \%)$; skor 1: Diş yüzeyinde $\% 50$ 'den daha az adeziv kalmıştır; skor 2,: Diş yüzeyinde $\% 50$ 'den daha fazla adeziv kalmıştır; skor 3: Tüm adeziv diş yüzeyinde kalmıştır (>90\%)
Bu çalışmada, braketler koptuktan sonra dişlerin mine yüzeylerini incelemek için, her bir gruptan birer örnek alınıp, SEM fotoğrafları değerlendi (Resim 4). I. gruptan alınan örnek sonucu; düzenli ve hafif pürüzlü bir yüzey görüntüsü elde edildi. Er:YAG lazer uygulanan diş (II. grup) yüzeyinde SEM' den alınan görüntülerden, değişikliğe uğramış hidroksiapatit kristalleri ile beraber pullu ve pürüzlü alanlar görülmüştür. Er:YAG+asit grubundan alınan dişin (III. grup) mine görüntüsünde, düzensiz ve ağır kaba yüzeyler, belirgin çıkıntılar ve bal peteği şekilli yüzey düzensizlikleri, daha fazla pörözite ve daha fazla yüzeysel erozyon, aynı zamanda erime alanları, fungiform çıkıntılar görüldü. Kumlama yöntemi ile mine pürüzlendirilen dişten (IV. grup) alınan SEM fotoğrafında, düzensiz bir yüzey görüntüsü olduğu ancak elde edilen pürüzlerin diğer 3 gruba göre daha sığ olduğu görüldü.

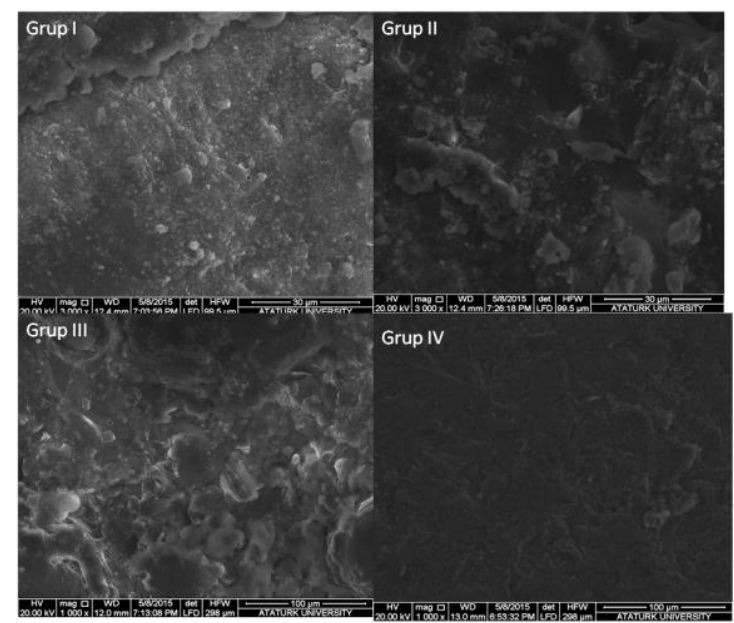

Resim 4. Her bir grup için braket koparıldıktan sonra mine yüzeylerinin SEM resimleri

\section{TARTIŞMA}

Ortodontik tedavilerde, braketlerin mine yüzeyine bağlanma dayanımları, tedavinin başarısını ve süresini etkileyen en önemli faktörlerden birisidir. Braket yapıştırıcıların mine yüzeyine mekanik olarak tutunabilmeleri için ise, mine yüzeyinin pürüzlendirilmesi gerekmektedir. ${ }^{1}$ Mine yüzeyinin pürüzlendirilmesinde, birçok yöntem kullanılmaktadır. ${ }^{2-7} \mathrm{Bu}$ çalışmada farklı mine pürüzlendirme yöntemlerinin (ortofosforik asit, kumlama ve Er:YAG lazer ve Er:YAG lazer+asit) kullanımı sonrası, SBS değerlerinin karşılaştırılması, SEM kulanılarak mine yüzeylerinde meydana gelen değişikliklerin

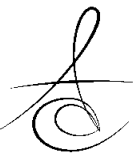


incelenmesi ve braketler koptuktan sonrası mine yüzeyinde kalan artık adeziv miktarlarının karşılaştırılması amaçlanmıştır.

Çalışmamızda elde edilen SBS test sonuçları sırayla grup I: 10.21 MPa - grup II: 9.33 MPa, grup III: $13.46 \mathrm{MPa}$, grup IV: $3.36 \mathrm{MPa}$ olarak bulunmuştur. Grup III' de 13.46 MPa'lık bağlanma değeriyle en yüksek bağlanmaya sahip iken, grup IV 'de $3.36 \mathrm{MPa}$ ile en düşük değer tespit edilmiştir. 6-8 MPa arasındaki SBS kuvvetlerinin ortodontik tedaviler için yeterli olduğu bildirilmiştir. ${ }^{28,29}$ Çalışmada karşılaştırılması yapı- lan her dört mine pürüzlendirme yönteminden sadece kumlama tekniğinin yetersiz SBS kuvvetine sahip olduğu, geri kalan üç yönteminde yeterli SBS değer- lerini sağladığı görülmektedir. Ancak Er:YAG+asit grubunun (grup III) SBS değerinin, diğer grupların ortalama değerlerinden istatistiksel olarak anlamlı düzeyde yüksek olduğu görülmektedir $(p<0.001)$. Bu gruba ait 13.46 MPa'lık ortalama değer, Retief 30 tarafından belirtilen diş minesinin kırılma değeri olan 14 MPa'a diğer grupların ortalama SBS değerine kıyasla daha yakındır, fakat yine de normal sınırlar içerisinde olduğunu düşünmekteyiz.

Mine pürüzlendirme işleminde en yaygın olarak kullanılan asitle pürüzlendirme yöntemidir. Asit ile pürüzlendirme işleminde yüzeyde demineralizasyon oluşmaktadır. Demineralize alan özellikle reçine materyalinin yapısında hava kabarcığının kaldığı ya da işlem sırasında iyi bir tükürük yalıtımının sağlanamadığı durumlarda uzun dönemde asit ataklarına ve çürük oluşumuna karşı elverişli duruma gelmektedir. ${ }^{9,30-32} \mathrm{Bu}$ gibi dezavantajları yapılan çalışmalarda asitle pürüzlendirme metoduna alternatif olarak farklı pürüzlendirme yöntemleri araştırılmıştır. Bunlardan biri ağız içi kumlama yöntemidir. Ortodontik tedavide \%37'lik ortofosforik asitle minenin pürüzlendirmesi geleneksel bir metottur ve "mikroetching" olarak adlandırılırken, kumlama ile gerçekleştirilen pürüzlendirme ise "makroetching" olarak adlandırılmaktadır. ${ }^{15,16,33}$ Yapılan bazı çalışmalarda kumlama yöntemiyle elde edilen SBS değerinin, asitle elde edilen değere yakın olduğu ve asitleme yöntemine alternatif olabileceği bildirilmiştir $^{34-36}$. Chan ve ark. ${ }^{36}$ ile Moritz ve ark.'nın ${ }^{35}$ yaptığı bazı çalışmalarda ise, en olumlu SBS ve mikrosızıntı değerlerinin kumlama yönteminin asitle pürüzlendirme ile kombine edildiğinde, elde edildiğini bildirmişlerdir. Dahası bazı in vitro çalışmalar ilave olarak asitle pürüzlendirme yapılmasa bile kumlama yönteminde, asitle pürüzlendirmeye benzer şekilde mine bağlanma yüzeyleri oluşturduğu gösterilmiştir. ${ }^{34}$ Yukarda bahsedilen çalışmaların aksine çoğu çalışmada kumlamanın diğer yüzey pürüzlendirme yöntemlerinden daha başarıSız olduğu ve daha düşük SBS değerleri saptandığı bildirilmiştir. $^{37,38} \mathrm{Bu}$ bulgu bizim çalışmayla uyumlu olup, kumlama yönteminin minenin asitle pürüzlendirme yöntemine alternatif olabileceğini düşünmemekteyiz.

Asitle pürüzlendirme yöntemine alternatif olarak araştırılan bir başka yöntem olan lazer ile pürüzlendirme yönteminin mineye yüksek oranda bağlanma ve bunun yanı sıra diş yapısında meydana getirdiği fizikokimyasal değişimlerle dişi asit atakları ve çürük oluşumuna karşı uzun dönemde daha dayanıklı duruma getirdiği belirtilmiştir. ${ }^{27}$ Bu çürük koruyucu etki Ca:P oranındaki değişiklikler, karbonatın azalması ve pirofosfat oluşumu ile ilişkilendirilmiştir. ${ }^{39}$ Asit ile pürüzlendirme sırasında dişin tükürükten çok iyi izole edilmesi gerekirken, lazer ile pürüzlendirme su soğutması ile yapıldığından tükürük izolasyonu gerekmemektedir. Bu da tükürük izolasyonunun zor sağlandığı klinik durumlarda (çocuk hasta, posterior bölge dişleri) teknik hassasiyetin az olması nedeni ile avantaj sağlamaktadır. $^{40}$ Lazerle pürüzlendirme asitle pürüzlendirme işlemine göre daha kısa sürede olması gibi avantajları da mevcuttur. Literatürde pürüzlendirme işlemlerinde Excimer, CO2, Nd:YAG, Er,Cr:YSGG, Er:YAG gibi lazerlerin kullanıldığı çok sayıda çalışma bulunmaktadır. Kullanılan lazer tipine bağlı olarak mine yüzeyinde 10-20 $\mu \mathrm{m}$ derinliğinde asit uygulamasına benzer bir pürüzlenme ve düzensizlik meydana geldiği bildirilmektedir. ${ }^{11,19,41}$ Biz çalışmamızda mine yüzeyinin pürüzlendirilmesi amaçlı, Er:YAG lazer kullanmayı tercih ettik.

Kullanılan lazerin gücüne göre mine yüzeyinde meydana getirdiği pürüzlendirme değişmektedir. 0.5, $0.75 \mathrm{~W}$ lazerle yapılan çalışmalarda yetersiz mine pürüzlendirme alanı klinik olarak yetersiz sınırlarda SBS değeri elde edilmiştir.1,1.5ve $2 \mathrm{~W}$ lazer pürüzlendirmenin kabul edilebilir sınırlarda SBS değeri elde edilmiş olan çalışmalar olmasına rağmen, $1 \mathrm{~W}$ lazer kulanımın yetersiz sonuçlar verdiğini gösteren çalışmalar yapılmış ve $1 \mathrm{~W}$ lazerin yeterliliği üzerinde kuşkular doğmuştur. Sonuç itibariyle $1.5 \mathrm{~W}$ ve $2 \mathrm{~W}$ lazerin uygun olduğu ortak görüşü elde edilmiştir. ${ }^{7,29}$ Bizde çalışmamızda 2 W lazer uygulamasını tercih ettik. 
Lazerle mine yüzeyinin pürüzlendirilmesi sonraSı, SBS kuvvetlerinin karşılaştırılması yapılan bazı çalışmalarda, bizim çalışmamızın aksine asitle pürüzlendirmenin lazerle pürüzlendirme yöntemine göre SBS kuvvetinin daha yüksek olduğu sonuçları elde edilmiştir. ${ }^{40,41-44}$, Bazı çalışmalarda ise bizim çalışmamıza benzer şekilde, her iki yönteminde birbirine yakın SBS sonuçları verdiği ve birbirlerinin alternatifi olabileceği sonuçları elde edilmiştir. ${ }^{11,22,23,42,45}$ Çalışmalarda bu farklı sonuçların sebebinin kullanılan lazerlerin tipi, dalga boyu, gücü, enerji miktarı, kullanım süresi gibi farklılıklardan kaynaklandığını düşünmekteyiz. Örneğin, çalışmamızın sonuçları Von Fraunhofer ve ark. ${ }^{11}$ ve Lin ve ark. $^{42}$ sonuçları ile uyumludur. Ancak RobertsHarry $^{43}$ ve Corpas- Pastor ve ark. ${ }^{44}$ sonuçları ile çelişmektedir. Bu çelişkinin Roberts-Harry ${ }^{43}$ ve CorpasPastor ve ark. ${ }^{44}$ kullandıkları lazer cihazlarının gücünün bizim kullandığımız lazer gücünden farklı ve düşük olmasından kaynaklandığını düşünmekteyiz. MartínezInsua ve ark. ${ }^{41}$ bizim çalışmanın aksine, Er:YAG lazer ile pürüzlendirilmiş mine yüzeyinde asit ile pürüzlendirilmiş mine yüzeyine oranla daha düşük SBS kuvvetinin olduğunu saptamışlar ve bunu SEM görüntülerinde görünen yüzey altı çatlaklara bağlamışlardır. Attrill ve ark. ${ }^{40}$ farklı frekanslarda Er:YAG lazer ya da geleneksel asit ile pürüzlendirilmiş mine yüzeylerinde kompozitlerin basma dayanımlarını incelemişler ve asit ile pürüzlendirilen grubun basma dayanımının farklı parametrelerde lazerin uygulandığı tüm gruplara ve hiç pürüzlendirmenin yapılmadığı negatif kontrol grubuna göre istatistiksel olarak anlamlı derecede yüksek olduğunu bulmuşlardır; lazer parametrelerinden yalnızca birinin basma dayanımının hiç asit uygulanmamış gruba göre istatistiksel olarak anlamlı derecede yüksek olduğunu bildirmişlerdir. Kim ve ark. ${ }^{45}$ Er:YAG lazer ya da asit ile pürüzlendirilmiş mine yüzeylerinde braketlerin çekme kuvvetlerine dayanımını incelemişler ve bizim çalışmamıza uyumlu olarak iki pürüzlendirme arasında istatistiksel olarak anlamlı bir farklılık bulamamışlardır. Lee ve ark. ${ }^{23}$ mine yüzeylerinde asit ile, lazer ile, hem asit hem lazer ile pürüzlendirme yapmışlar ve pürüzlendirilmiş yüzeylerde ortodontik braketlerin SBS değerlerini incelemişlerdir. Lazer ile pürüzlendirilmiş yüzey ile asit ile pürüzlendirilmiş yüzey arasında bizim çalışmamızda olduğu gibi, SBS kuvvetleri açısından istatistiksel olarak anlamlı bir farklılık bulunmadığını, lazer ile pürüzlendirilmiş örneklerde ise asit+lazer ya da lazer+asit uygulanmış örneklere oranla SBS değerinin yine bizim çalışmamızda olduğu gibi istatistiksel olarak anlamlı derecede yüksek olduğunu saptamışlardır; ayrıca araştırmacılar elde ettikleri bulguların benzer çalışmalardan farklı oluşunu çalışmadan önce en uygun lazer parametresinin belirlenmesi için SEM analizine dayalı bir pilot çalışma yapmalarına bağlamışlardır. Aynı şekilde bizim çalışma sonuçlarımıza uyumlu olarak, Türköz ve Ulusoy ${ }^{22}$ yaptıkları çaIışmada, Er:YAG lazer ve devamında asit kullanımının SBS değerini arttırdığı sonucuna varılmıştır.

Çalışmamızda braketler koparıldıktan sonra 10x stereomikroskop büyütme ile mine yüzeyleri incelenmiştir. IV. grupta mine yüzeyinde hemen hemen hiç rezin artığı bulunmazken (skor:0), III. grupta makaslama bağlanma kuvvetinin fazla olması sebepli olduğunu düşündüğümüz en fazla rezin artığı görüldü (skor:2 ve 3). I. ve II. gruplarda ise \%50'den az oranda (skor:0,1) rezin artığı saptanmıştır. Mine yüzeyinin pürüzlendirilmesi braketin kopmasını engelleyecek düzeyde olmalıdır. Ancak iyi bir tutuculuk sağlamak pahasına, mine yüzeyinde ağır hasarlar oluşturulmaması gerektiği ve aynı zamanda braketlerin sökülmesi sırasında da mine yüzeyinde hiç bir zarar oluşturulmaması veya zararın minumum düzeyde olması gerektiğini düşünmekteyiz.

\section{SONUÇ}

Bizim çalışmanın sonucu olarak, kumlama yönteminin asitle pürüzlendirme yöntemine alternatif olmadığı, çalışma verilerimizin sonuçlarına göre her ne kadar SBS en fazla III. grupta (Er:YAG+asit) olsa da, mine yüzeyinde en fazla rezin bırakması ve mine yüzeyinde kalan yapıştırıcının temizlenmesi sırasında diş yüzeyine zarar verilebileceği ve ayrıca hasta başında geçirilecek zamanıda artıracağı sebebiyle çalışmamızın sonucu olarak Er:YAG+asit uygulamasının ideal pürüzlendirme yöntemi olarak düşünmemekteyiz. Çalışmamızın sonucu olarak Er:YAG lazerin asitle pürüzlendirme yöntemine alternatif olabileceği görüşündeyiz.

\section{KAYNAKLAR}

1. Urabe $\mathrm{H}$, Rossouw PE, Titley KC, Yamin C. Combinations of etchants, composite resins, and bracket systems: an important choice in orthodontic bonding procedures. Angle Orthod 1999; 69:267-75. 
2. Millett D T, McCabe J F , Bennett T G , Carter NE Gordon $\mathrm{P} \mathrm{H}$. The effect of sandblasting on retention of first molars orthodontic bands cemented with glass ionomer cement. British Journal of Orthodontics 1995; 22:161-9.

3. Çağlaroğlu M, Çatalbaş B,Gelgör E. Farklı Yöntemlerle Pürüzlendirilmiş Mine Yüzeylerinin Fotoğrafik Görüntülerinin Karşılaştırılması. Atatürk Üniv Diş Hek Fak Derg 2012; 22: 154-9.

4. Büyükyılmaz $T$, Zachrisson $Y \varnothing$, Zachrisson B U Improving orthodontic bonding to gold alloy. Am J Orthod Dentofacial Orthop 1995;108:510-8.

5. Chung $\mathrm{KH}$, Hwang YC Bonding strengths of porcelain repair systems with various surface treatments. Journal of Prosthetic Dentistry 1997; 78:267 -74.

6. Takeda FH, Harashima $T$, Eto JN , Kimura $Y$, Matsumoto K. Effect of Er:YAG laser treatment on the root canal walls of human teeth: a SEM study. Endodontic Dental Traumatology 1998;14:270 -3.

7. Üşümez $S$, Orhan $M$, Üşümez $A$. Laser etching of enamel for direct bonding with an Er,Cr:YSGG hydrokinetic laser system. Am J Orthod Dentofacial Orthop 2002;122:649 -56.

8. Buonocore MG. A simple method of increasing the adhesion of acrylic filling materials to enamel surfaces. J Dent Res. 1955;34:849-53.

9. Eidelman E. Intentional sealing of occlusal dentin caries: a controversial issue. Pediatr Dent 1993;15:312.

10. Olsen ME , Bishara SE , Damon P , Jakobsen JR Comparison of shear bond strength and surface structure between conventional acid etching and air abrasion of human enamel. Am J Orthod Dentofacial Orthop 1997;112:502-6.

11. Von Fraunhofer JA, Allen DJ, Orbell GM. Laser etching of enamel for direct bonding. Angle Orthod 1993;63:73-6.

12. Walsh L, Abood D, Brockhurst PJ. Bonding of composite resin to carbon dioxide laser-etched human enamel. Dent Mater 1994; 10:162-6.

13. Melendez EJ, Arcoria CJ, Dewald JP, Wagner MJ. Effect of laseretch on bond strengths of glass ionomers. J Prosthet Dent 1992; 67:307-12.

14. Hogervorst WW, Feilzer AJ, Prahl-Andersen B. The air-abrasion technique versus the conventional acid-etching technique: a quantification of surface enamel loss and a comparison of shear bond strength. Am J Orthod Dentofacial Orthop 2000; 117:20-6.

15. Canay S, Kocadereli I, Akça E. The effect of enamel air abrasion on the retention of bonded metallic orthodontic brackets. Am J Orthod Dentofacial Orthop 2000;117:15-9.

16. Reisner KR, Levitt $H L$, Mante F. Enamel preparation between the use of a sandblaster and current techniques. Am J Orthod Dentofacial Orthop 1997; 111: 366-73.

17. Ozer T, Basaran G, and Berk N. Laser etching of enamel for orthodontic bonding. Am J Orthod Dentofacial Orthop 2008;134:193-7.

18. Basaran G, Ozer T, Berk N, and Hamamci O. Etching enamel for orthodontics with an erbium, chromium:yttriumscandium- gallium-garnet laser system. Angle Orthodontist 2007;77(1): 117-123.

19. Visuri SR, Gilbert JL, Wright DD, Wigdor HA, Walsh JT Jr. Shear strengths of composite bonded to Er:YAG laser prepared dentin. J Dent Res 1996; 75:599-605.

20. Ariyaratnam MT, Wilson MA, Mackie IC, Blinkhorn AS. A comparison of surface roughness and composite/enamel bond strength of human enamel following the application of the Nd:YAG laser and etching with phosphoric acid. Dent Mater 1997;13:51-55.

21. Fraunhofer J A, Allen D J, Orbell G M. Laser etching of direct bonding. Angle Orthodontist 1992; 63:73-6

22. Türköz C,Ulusoy C. Evaluation of different enamel conditioning techniques for orthodontic bonding. Korean J Orthod 2012;42:32-8.

23. Lee BS, Hsieh TT, Lee YL, Lan WH, Hsu YJ, Wen $\mathrm{PH}$, Lin CP. Bond strengths of orthodontic bracket after acid-etched, Er:YAG laser-irradiated and combined treatment on enamel surface. Angle Orthodontist 2003;73:565-70.

24. Liberman R, Segal TH, Nordenberg D, Serebro LI. Adhesion of composite materials to enamel: comparison between the use of acid and lasing as pretreatment. Lasers Surg Med 1984;4:323- 7.

25. Shahabi S, Brockhurst PJ, Walsh LJ. Effect of tooth-related factors on the shear bond strengths obtained with $\mathrm{CO} 2$ laser conditioning of enamel. Aust Dent J 1997;42:81-4. 
26. Whitters CJ, Strang R. Preliminary investigation of a novel carbon dioxide laser for applications in dentistry. Lasers Surg Med 2000;26:262-9.

27. Hossain M, Nakamura $Y$, Tamaki $Y$, Yamada $Y$, Murakami $Y$, Matsumoto K. Atomic analysis and knoop hardness measurement of the cavity floor prepared by Er,Cr:YSGG laser irradiation in vitro. J Oral Rehabil 2003;30:515-21

28. Årtun J, Bergland S Clinical trials with crystal growth conditioning as an alternative to acid-etch enamel pretreatment. Am J Orthod 1984; 85:333 40.

29. Reynolds I R A review of direct orthodontic bonding. British Journal of Orthodontics 1975; 2 :171-80.

30. Retief DF, Dreyer CJ, Gavron G: The direct bonding oforthodontic attachments to teeth by means of an epoxy resin adhesive. Am J Orthod 1970; 58: 21-40.

31. Donnan MF, Ball IA. A double-blind clinical trial to determinethe importance of pumice prophylaxis on fissure sealant retention. Br Dent J 1988;165:2836.

32. Moshonov J, Stabholz A, Zyskind D, Sharlin E, Peretz B. Acidetched and erbium:yttrium aluminium garnet laser-treated enamel for fissure sealants: a comparison of microleakage. Int ] Paediatr Dent 2005; 15:205-9.

33. Goldstein RE, Parkins FM. Using air-abrasive technology to diagnose and restore pit and fissure caries. J Am Dent Assoc 1995; 126: 761-6.

34. Hatibovic-Kofman S,Wright GZ, Braverman I. Microleakage of sealants after conventional, bur, and air-abrasion preparation of pits and fissures. Pediatr Dent 1998; 20:173-6.

35. Moritz A, Gutknecht N, Schoop U, Goharkhay K, Wernisch J, Sperr W. Alternatives in enamel conditioning: a comparison of conventional and innovative methods. J Clin Laser Med Surg 1996; $14: 133-6$.

36. Chan DC, Summitt JB, Garcia-Godoy F, Hilton TJ, Chung $\mathrm{KH}$. Evaluation of different methods for cleaning and preparing occlusal fissures. Oper Dent 1999; 24:331-6.

37. Berry EA 3rd, Ward M. Bond strength of resin composite to airabraded enamel. Quintessence Int 1995; 26:559-62.
38. Ellis RW, Latta MA, Westerman GH. Effect of air abrasion andacid etching on sealant retention: an in vitro study. Pediatr Dent 1999; 21:316-9.

39. Klein AL, Rodrigues LK, Eduardo CP, Nobre dos Santos M, Cury JA. Caries inhibition around composite restorations by pulsed carbon dioxide laser application. Eur J Oral Sci 2005;113:239-44.

40. Attrill DC, Farrar SR, King TA, Dickinson MR, Davies RM, Blinkhorn AS. Er:YAG $(\lambda=2.94 \mu \mathrm{m})$ laser etching of dental enamel as an alternative to acid etching. Lasers Med Sci 2000, 15: 154-161.

41. Martinez-Insua A, Da Silva Dominguez L, Rivera FG, Santana- Penin UA. Differences in bonding to acid-etched or Er:YAGlaser- treated enamel and dentin surfaces. J Prosthet Dent 2000; 84:280-8.

42. Lin S, Caputo AA, Eversole LR, Rizoiu IM: Topographical characteristics and shear bond strength of tooth surfaces cut with a laser-powered hydrokinetic system. J Prosthet Dent 1999; 82: 451-5.

43. Roberts-Harry DP: Laser etching of teeth for orthodontic bracket placemenl: a preliminary clinical study. Lasers Surg and Med 1992; 12: 46770.

44. Corpas-Pastor L, Moreno JV, Garrido JDLG, Muriel VP, Moore K, Elias A: Comparing the tensile strengths of brackets adhered to laser-etched enamel vs. Acid-etched enamel. JADA 1997; 128: 732-7.

45. Kim JH, Kwon OW, Kim HI, Kwon YH. Effectiveness of an Er:YAG laser in etching the enamel surface for orthodontic bracket retention. Dent Mater ] 2005; Dec; 24: 596-602.

\section{Yazışma Adresi:}

Dr. Fidan Alakuş Sabuncuoğlu,

Department of Orthodontics, Center for Dental Sciences, Gulhane School of Medicine, Ankara, Turkey

Telephone: +90 (532) 7228904

e-mail: fidansabuncuoglu@yahoo.com.tr 